Article

\title{
Fabrication and Evaluation of a Cabbage Harvester Prototype
}

\author{
Mohamed Ibrahim El Didamony ${ }^{1, * \mathbb{D}}$ and Ahmed Mohamed El Shal ${ }^{2}$ (D) \\ 1 Department of Agricultural Engineering, Tanta University, Tanta 31527, Egypt \\ 2 Department of Agricultural Engineering, Zagazig University, Zagazig 44511, Egypt; \\ elshal_a@yahoo.com or amelshal@agri.zu.edu.eg \\ * Correspondence: agri.mid@gmail.com or el-didamony@agr.tanta.edu.eg; Tel.: +20-1013027627
}

Received: 17 November 2020; Accepted: 7 December 2020; Published: 14 December 2020

\begin{abstract}
A cabbage harvester prototype was fabricated and tested to save time, cost, and labor for harvesting. This harvester was designed for harvesting operations to drive the prototype and control the harvester. The single-row prototype harvesting meets the functional requirements of the physical properties of the Egyptian cabbage. The performance of the harvester prototype was evaluated on two shapes of cutter disc, four cutter disc speeds, and four cutter disc angles; these parameters were assessed at $88 \%$ moisture content of the cabbage head and average forward speed of $1.5 \mathrm{~km} / \mathrm{h}$. The results demonstrated that the serrated edge cutter discs and $900 \mathrm{rpm}$ disc speed produced actual productivity of $12.56 \mathrm{ton} / \mathrm{h}, 2.28 \mathrm{~kW}$ power requirements, $0.18 \mathrm{~kW} \mathrm{h/ton} \mathrm{specific}$ energy requirement, and of $3.66 \$ / \mathrm{h}$ operating cost. It turns out that the harvester did not do major harm to the cabbage and less than $4 \%$ damage. Operating the harvester at the optimum parameters saves cost and time compared with manual harvesting.
\end{abstract}

Keywords: cabbage; harvester prototype; single row; power required

\section{Introduction}

The Egyptian cabbage (Brassica oleracea var. capitata) is mainly harvested manually which is laborious, time consuming, and costly. In Egypt, the total cultivated area of cabbages and other brassicas is about 17,250 hectares which produce 525,410 tons [1]. As a result of the importance of cabbage attempts have been made to promote mechanization by developing an efficient harvester assuming that cabbages are planted in a row on each ridge. The cutting force of the broccoli stalk greatly influences the speed of the blade, with the lowest force $(73.40 \mathrm{~N})$ resulting at the maximum speed $(25.63 \mathrm{~cm} / \mathrm{s})$. The cutting force is influenced by the stalk area and the perpendicular stalk diameter [2].

A manually guided cutting system for selectively harvesting broccoli during the first harvest season was developed and tested pneumatically powered harvesting, with the device working on a triple or double row of broccoli. They observed that the rate of the harvest was not influenced by the method of an activity or by the various forms of planting but increased dramatically with the subsequent harvest. For two fields, the average manual harvest rate was 7.4 heads/min and the average cumulative harvest for the unit was 11.1 heads/min. It was discovered to be $50 \%$ quicker than manual harvesting. In the second season, a new cutting system was tested to cut two double rows of broccoli in one pass using the walking process. In the second season, the total average harvest rate with the cutting instrument was also higher, 11.4 heads/min [3].

Agri-Food and agriculture engineers of Canada, along with Universo Hydraulique, improved a mechanical cabbage harvester. It was a single pass field unit mounted on a tractor. The picker was the fundamental measure of the undertaking, which picked up the cabbages using two belts and raised them to a disc blade that cut the stalks advantageously. The stature is uniform, beginning with one 
cabbage and then the accompanying one, and can be reacclimated with the leaves of the cabbage. Roots tumble to the ground and two identical belts give the cabbages to a slanted conveyor which gives the cabbages up to the conveyor belt introduced on the opposite side of the tractor. Five experts on a trailer, pulled by another tractor, get the cabbages and carefully position them in hoppers. Tests were conducted on two commercial farms, with an average rate of 3277 cabbages per hour being harvested by a team of eight workers. By mechanical harvesting, the cabbages became much more affected than by pure hand harvesting. However, the field rig operation caused more harm when the automatic harvester was compared to manual harvesting using a field rig elevator. Long-term storage studies were carried out at six different locations and found that mechanically processed cabbages could be preserved satisfactorily for up to 4 months and even up to 6 months in some instances [4].

Another investigation stated that the height at which the stalks are cut is critical and should be measured from a fixed reference point rather than from the ground up [5].

When it was tough to pull the cabbages, a digger point was used to unbend the soil and make pulling the cabbages easier. To pull a cabbage root out of light soil, an average force of $110 \mathrm{~N}$ is needed, but forces up to $250 \mathrm{~N}$ are required in heavy soils. A series of biaxial screw augers and a set of feed belts form the pulling mechanism. The pulling device separated Chinese cabbages from the ground and transferred them. The wrapper leaves are separated by the cutting mechanism that consists of a spinning disk-cutter while the heads are transported by the pulling mechanism. Under field conditions, the machine worked continuously to pull Chinese cabbages, cut the wrapper leaves and leave the heads in the field, a one-row walking harvester prototype with pulling and cutting mechanisms was built and tested. A tractor-mounted-type harvester was fabricated and strengthened by the installation of an elevator, a bulk bin, and a height controller system after assessing the efficiency of the walking-type harvester. The unit was run at a 2 acre/h harvest rate. For the harvesting process, two men were needed. Heads were not lost and were manually retrimmed and returned to the sector. Approximately $30 \mathrm{man} \mathrm{h/10}$ acre was the overall harvesting work rate including retrimming by hand [6].

A harvester mounted on a tractor has been planned and fabricated, which utilized a cutter disc observed to cut off broccoli heads from the plants, a belt, and flight transports to raise the heads to a flat belt cross transport that conveys the reaped heads into a pallet box situated on a cart towed close to the reaper. Harvest paces of 60 to 90 heads/min in the line seemed doable. Slight harm to the broccoli heads was seen which was assessed to be acknowledged for handling broccoli. A single row harvesting framework for broccoli relies for the most part upon cultivar execution more than machine execution [7].

A cut-off saw system has been developed and validated for the selective broccoli harvest. The system consisted of a hydraulic motor and a saw blade mounted on a swing arm that was hydraulically actuated and connected to the side of a tractor by a vertical prismatic joint to allow the cutting height to be changed. Preliminary research over the growing season showed that continuous harvesting was possible at rates of up to 40 heads/min. While harvesting any other plant, a rate of 23 heads/min was feasible. Plants were harvested with 80 percent precision for harvest from the operator's seat. The harvested heads or immature plants remaining in the field showed no visible damage [8].

Evaluated a single-pass mechanical broccoli harvester prototype which was operated at field speeds ranged from $1 \mathrm{~km} / \mathrm{h}$ to $4.6 \mathrm{~km} / \mathrm{h}$. He concluded that the optimum field speed ranged from 2.5 to $3.2 \mathrm{~km} / \mathrm{h}$, these field speeds translate into harvest rates of 0.44 to $2.1 \mathrm{ha} / \mathrm{da}$, assuming a plant spacing of $0.3 \mathrm{~m}$, the harvester has a harvesting rate range of 130 to 175 plants per minute and harvested broccoli is good quality with little or no damage to the heads [9].

For paddy stems cutting energy and blade optimal parameters, a pendulum style impact shear test system was developed and installed. The findings suggest an angle for bevel blades of $28^{\circ}$, an oblique angle of $30^{\circ}$, an angular incline of $35^{\circ}$, and a speed of blades of $2.24 \mathrm{~m} / \mathrm{s}$ [10]. 
The optimum operating parameters were identified, which were $40^{\circ}$ sliding angle, $300 \mathrm{~mm} / \mathrm{min}$ cutting speed, and $35 \mathrm{~mm}$ cutting diameter for cabbage root to minimize splitting failure levels [11]. Other previous studies also explored the effect of blade angle and blade geometry on energy reduction.

Many of these studies showed that for a rotating knife-type sugarcane base cutter, a blade peripheral velocity of $13.8 \mathrm{~m} / \mathrm{s}$, oblique angle of $35^{\circ}$ and tilt angle of $27^{\circ}$ are ideal for a rotating knife-type sugarcane base cutter [12].

It was revealed that the optimum knife edge angle, shear angle, oblique angle, and rake angle were $25^{\circ}, 40^{\circ}, 40^{\circ}$ and $40^{\circ}$, respectively for kenaf stems [13].

The quick overview gatherer appended to a self-pushed crawler tractor was planned and fabricated, including a picking instrument, lifting component, double plate saws, leaf separator and hydraulic oil system. This reaper gets cabbage heads with a couple of picking digging tools and conveys them utilizing a couple of crossover belts. In the conveyance cycle, the plant roots are cut by a double turning circle saw and disposed of toward the last of tooth-chains. In the back of the reaper, a pivoting elastic roller eliminates the wrapping leaves from the balls. In the end, the cabbage balls are stacked into a hopper. After the lab and preparatory field tests, a portion of the key segments were improved. The outcomes exhibited the gatherer had a decent ability, attainability, and profitability. While working at a speed went from 0.2 to $0.4 \mathrm{~m} / \mathrm{s}$, the reaper played out a decent gathering quality, whose picking rate was over $90 \%$, conveying rate was almost $100 \%$, the precise cutting rate changed from $57.8 \%$ to $75.0 \%$, leaf detaching rate changed from $68.0 \%$ to $80.0 \%$, and reaping harvesting loss was under $6.7 \%$. In addition, they found that the ready consistency and cabbage assortment were determinant factors that impacted the reaping quality. By correlation, the reaping quality in the trial fields was far superior to that in conventional fields [14].

Different kinds of stalks demonstrate different mechanical properties in cutting processes, even for the same kind of stalks, the mechanical properties are different due to different crop maturity, moisture content and planting site. The main problem is that there are no machines suitable for large cabbage varieties (heavyweight), cabbage cultivation in Egypt is spread over small agricultural areas and it is not cultivated using agricultural mechanization, as there was a difference between agricultural distances between the many farmers. Therefore, this study aimed to fabricate and evaluate a cabbage harvester prototype to suit all cultivation distances for farmers, being easy to disassemble, install, adjust, maintain, and it works in small and limited agricultural holdings. The specific objectives of this research were to fabricate a harvester prototype for cabbage, identify the optimum operating, engineering parameters of the fabricated harvester, and decrease costs of labor and energy requirements.

\section{Materials and Methods}

The cabbage harvester prototype was assembled at a private workshop at El Ibrahimia, Al Sharkia Governorate, Egypt. The experiment was carried out on clay soil at a private farm in Sharkia Mobasher over the winter season of 2020 and for harvesting cabbages (Kahera hybrid variety).

\subsection{The Cabbage Plant (Kahera Hybrid)}

In Egypt, cabbage is produced as a row crop with $800 \mathrm{~mm}$ distance between rows and $700 \mathrm{~mm}$ distance between cabbages on the same row. The physical and mechanical properties of cabbage plants are given in Table 1. 
Table 1. Physical and mechanical properties of cabbage (Kahera hybrid).

\begin{tabular}{cc}
\hline Cabbage Characteristic & Average Value \\
\hline Stem height above the ground, $\mathrm{mm}$ & 200 \\
Stem diameter, $\mathrm{mm}$ & 63 \\
Cabbage diameter, $\mathrm{mm}$ & 560 \\
Cabbage height from the ground, $\mathrm{mm}$ & 630 \\
Mass of Cabbage, $\mathrm{kg}$ & 7.5 \\
Cut force of cabbage stem, $\mathrm{N}$ & 230 \\
\hline
\end{tabular}

\subsection{Prototype Specification}

The prototype of the cabbage harvesting machine consisted of five main parts including mainframe, cutter unit, gearbox, engine, power transmission and draw to adjust the tilt angle of the cutter disc, as shown in Figure 1a-c.
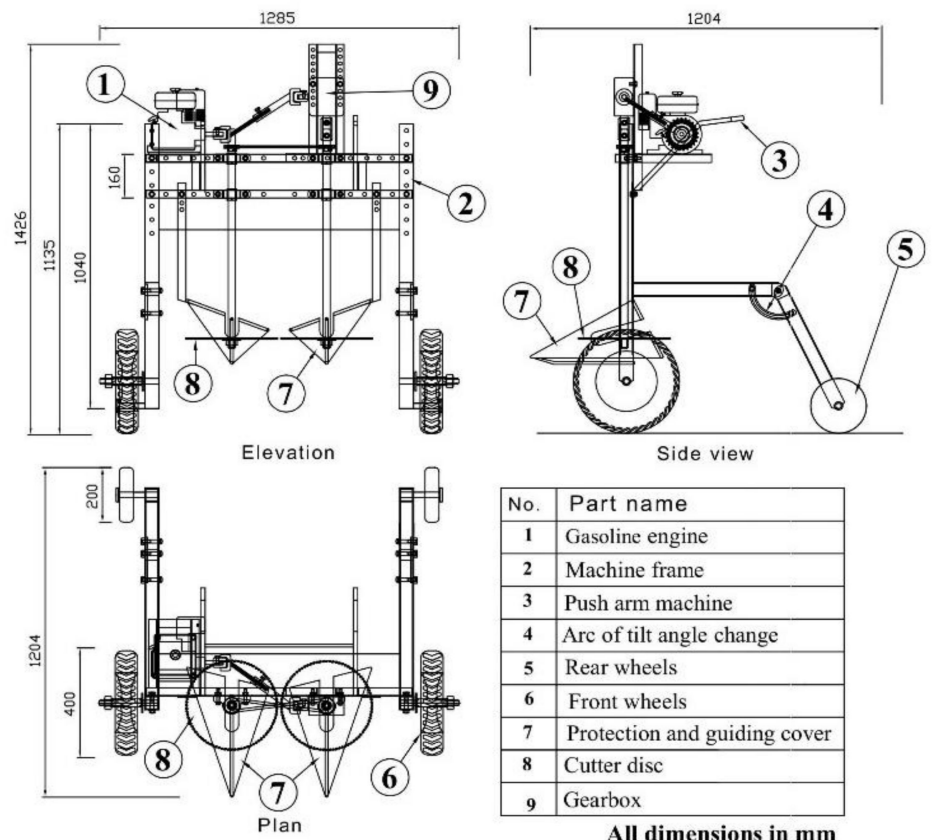

(a)
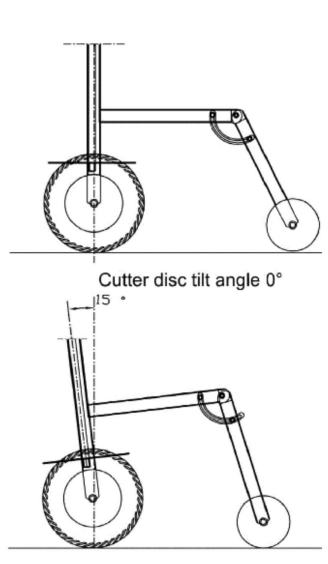

Cutter disc tilt angle $15^{\circ}$

(b)

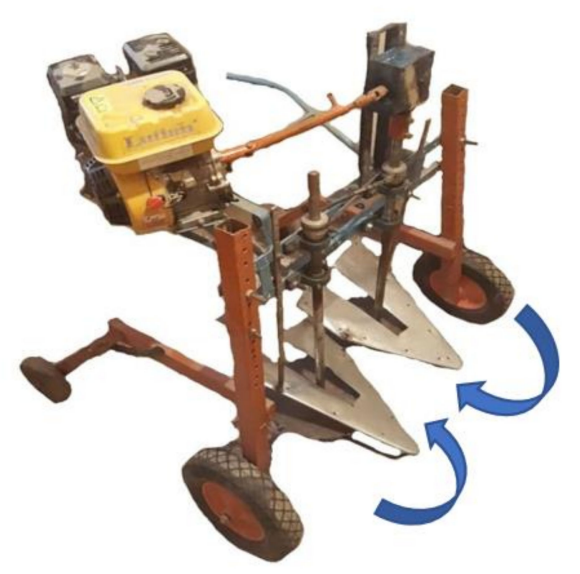

(c)

Figure 1. (a) Cabbage harvesting prototype. (b) The tilt angles of the cutter disc. (c) A photograph of cabbage harvesting prototype. 
The mainframe of the cabbage harvesting machine was constructed from iron bars L-shape with dimensions of $30 \times 30 \times 3 \mathrm{~mm}$ and a square sheet of iron with dimensions of $50 \times 50 \times 3 \mathrm{~mm}$. The total dimensions of the mainframe were $1204 \mathrm{~mm}$ for length, $1285 \mathrm{~mm}$ for width, and $1426 \mathrm{~mm}$ for height.

The cutting unit consisted of two main parts. The first part was cutting discs and there were two shapes, including a smooth shape and a serrated shape. It had a diameter of $330 \mathrm{~mm}$ made from sheet metal iron with $4 \mathrm{~mm}$ thickness. The second part was two steel shafts made of steel bar metal with dimensions of $25 \mathrm{~mm}$ diameter and $800 \mathrm{~mm}$ length and each shaft was fixed on the mainframe with two high-speed bearings. The gearbox was used to change the transmission direction to reduce cutter disc speeds (1:0.5).

The power produced by the gasoline engine was transmitted to a gearbox shaft by a universal joint and another shaft of gearbox connected to a steel shaft, to transfer the motion between the two steel shafts by pulleys. The pulley was fixed on the first steel shaft with a diameter of $50 \mathrm{~mm}$ and the second pulley was fixed on the second steel shaft of the cutter unit with a diameter of $50 \mathrm{~mm}$ and using one V-belt (Figure 2). Both cutter discs were fixed at the end of the shafts.

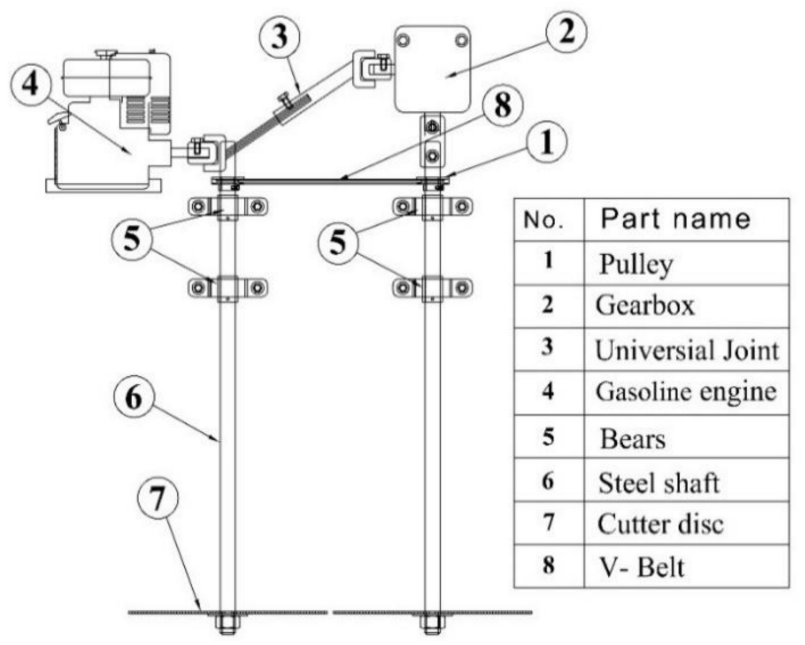

Figure 2. Power transmission system.

The Lutian model made in China with gasoline engine power was used for this study that can work at a maximum speed of $3600 \mathrm{rpm}$ and $4.8 \mathrm{~kW}$ power.

\subsection{Experimental Conditions}

The performance of the cabbage prototype harvester machine was studied under four cutter disc speeds of 400, 500, 700, and $900 \mathrm{rpm}$; four cutter disc angle of $0,15,35$, and $50^{\circ}$; two shapes of cutter disc, smooth disc and serrated disc. The harvester was evaluated at $88 \%$ as the optimal moisture content of the cabbage head and average forward speed of $1.5 \mathrm{~km} / \mathrm{h}$.

\subsection{Instruments}

A scale balance (OHAUS-USA) model made in China, Guangzhou was used for massing the cabbage samples. A laser tachometer was used for measuring the rotating speed of the motor shaft pulleys and cutter discs. To measure the cabbage stem diameter, a mechanical Vernier calliper with an accuracy of $0.01 \mathrm{~mm}$ was used. The moisture content of the cabbage stem was determined in compliance with the ASAE S358.22 standard [15]. 


\subsection{Measurements}

Actual field capacity was computed using the following equation:

$$
\text { Afc }=\frac{1}{\mathrm{~T}_{\text {total }}}
$$

where Afc is actual field capacity in (ha/h) and $\mathrm{T}_{\text {total }}$ is the total actual time in (h/ha).

The following equation was used to estimate power $(\mathrm{P})$ as provided by [16].

$$
\mathrm{P}=(\mathrm{FC} / \mathrm{c}) \times(\eta \mathrm{th} / 100) \times \mathrm{HV}
$$

where $\mathrm{P}$ is the required power in $(\mathrm{kW}) ; \mathrm{FC}$ is fuel consumption in $(\mathrm{kg} / \mathrm{h}) ; \eta$ th is the thermal efficiency in (\%); $\mathrm{HV}$ is the fuel heating value in $(\mathrm{kJ} / \mathrm{kg}) ; \mathrm{c}$ is constant (3600).

The specific energy requirement was calculated as follows:

$$
\text { Ser }=\frac{P}{A p}
$$

where Ser is specific energy requirement ( $\mathrm{kW} \mathrm{h/ton);} \mathrm{P} \mathrm{is} \mathrm{the} \mathrm{required} \mathrm{power} \mathrm{in}(\mathrm{kW})$; and Ap is actual productivity in (ton/h).

The equation as provided by [16].

$$
\mathrm{AC}=\frac{(\mathrm{FC} \%) \mathrm{P}}{100}+\frac{\mathrm{CA}}{\mathrm{Swe}}[(\mathrm{R} \& \mathrm{M}) \mathrm{P}+\mathrm{L}+\mathrm{O}+\mathrm{F}+\mathrm{T}]
$$

where $\mathrm{AC}$ is the annual cost of the operating machine in (\$/year); FC\% is the annual fixed cost percentage; $\mathrm{P}$ is the purchase price of the machine in (\$); $\mathrm{c}$ is a constant (10); $\mathrm{A}$ is the annual harvested area in (ha); $\mathrm{S}$ is the forward speed in $(\mathrm{km} / \mathrm{h}) ; \mathrm{w}$ is the effective width of action of the machine in $(\mathrm{m})$; $\mathrm{e}$ is the field efficiency in (\%); $\mathrm{R}$ and $\mathrm{M}$ are the repair and maintenance costs in (\$/h); $\mathrm{L}$ is labor rate in $(\$ / h) ; \mathrm{O}$ is oil cost in $(\$ / \mathrm{h}) ; \mathrm{F}$ is fuel cost in $(\$ / \mathrm{h})$; and $\mathrm{T}$ is the cost of tractor use by machine in $(\$ / \mathrm{h})$ and $\mathrm{T}=0$ if self-propelled.

$$
\mathrm{Oc}=\frac{\mathrm{Mc}}{\mathrm{Ap}}
$$

where Oc is operating cost in (\$/ton); Mc is machine cost in $(\$ / \mathrm{h})$; and Ap is actual productivity in (ton/h).

\subsection{Energy Requirements for the Cutting Action Using the Rotary Disc Cutter}

Equation of motion, as shown in Figure 3.

$$
\begin{gathered}
\theta=\omega t \\
\omega=2 \pi N \\
N=r p m \\
X=V t+R \cos \theta \\
X=V t+R \cos \omega t \\
\dot{X}=\left(\frac{d X}{d t}\right)=V+\omega R \sin \omega t \\
\ddot{X}=\left(\frac{d \dot{X}}{d t}\right)=-\omega^{2} R \cos \omega t
\end{gathered}
$$


where $\theta$ is angle; $N$ is rotating speed; $R$ is the disc radius; $X$ is the instantaneous displacement; $\dot{X}$ is motion velocity; $\ddot{X}$ is the acceleration of motion; $\mathrm{V}$ is the forward speed of the cabbage harvester; and $\omega$ is angular velocity $=2 \pi \mathrm{N} ; \mathrm{t}=$ Time.

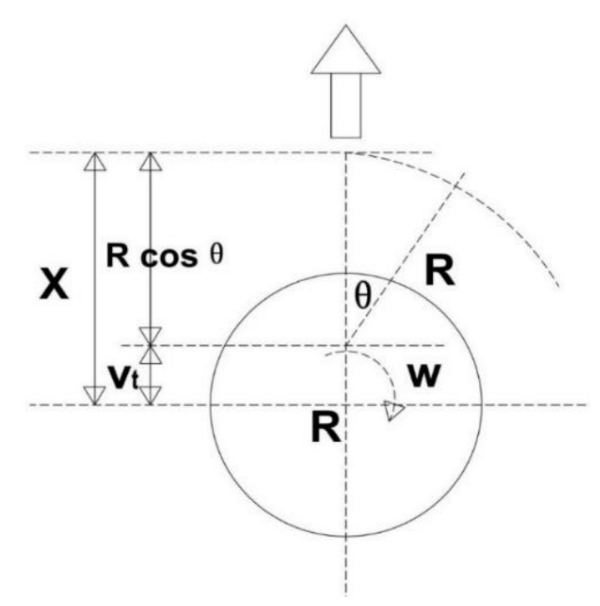

Figure 3. The cutting mechanism of the disc cutter.

\subsection{Energy Requirements}

$$
\frac{\mathrm{Ke}}{\mathrm{rev}}=0.5 \mathrm{~m} \dot{\mathrm{X}}^{2}
$$

where Ke is kinetic energy; rev is the revolution of the cutter disc; and $\mathrm{m}$ is mass of the cutter disc = $(\mathrm{W} / \mathrm{g})$ weight of disc/acceleration of gravity.

$$
\frac{\mathrm{P}}{\mathrm{rev}}=\mathrm{Ke} \times \frac{0.745}{\mathrm{t}} \times 75
$$

where $\mathrm{p}$ is power $(\mathrm{kW})$; rev is the revolution; Ke is kinetic energy $(\mathrm{N} \mathrm{M})$; and $\mathrm{t}$ is the time of one revolution $=60 / \mathrm{N}$.

$$
\mathrm{Cp}=\frac{\mathrm{P}}{\mathrm{rev}} \times \mathrm{Car}
$$

where $\mathrm{Cp}$ is cutting power $(\mathrm{kW})$; $\mathrm{P}$ is power $(\mathrm{kW})$; rev is the revolution; and Car is cross-section area revolution $\left(\mathrm{cm}^{2}\right)$.

\section{Results and Discussion}

\subsection{Actual Productivity}

Cutter disc tilt angle, type of edge cutter disc and cutter disc speed were the principal parameters governing the actual productivity and field efficiency of the fabricated cabbage harvester prototype (Table 2). It shows that, for the serrated edge cutter disc, at an average $1.5 \mathrm{~km} / \mathrm{h}$ forward speed and at cutter disc speed of $900 \mathrm{rpm}$, increasing the cutter disc tilt angle from 0 to $35^{\circ}$ led to increased actual productivity with average values ranging from 9.02 to 12.56 ton/h, respectively. Vice versa, increasing the cutter disc tilt angle from 35 to $50^{\circ}$, produced less actual productivity with average values ranging from 12.56 to $8.63 \mathrm{ton} / \mathrm{h}$, respectively.

For the smooth edge cutter disc at an average $1.5 \mathrm{~km} / \mathrm{h}$ forward speed and cutter disc speed of $900 \mathrm{rpm}$, increasing the cutter disc tilt angle from 0 to $35^{\circ}$ increased the average actual productivity values from 6.58 to 9.04 ton/h, respectively.

Vice versa, from 35 to $50^{\circ}$, decreased the average actual productivity values from 9.04 to $6.28 \mathrm{ton} / \mathrm{h}$, respectively. 
The harvest rate with the fabricated prototype (14-28 heads/min) for the serrated edge cutter disc and the harvest rate with the prototype (10-20 heads/min) for the smooth edge cutter disc at an average forward speed of $1.5 \mathrm{~km} / \mathrm{h}$.

Table 2. Actual productivity.

\begin{tabular}{ccccccccc}
\hline & \multicolumn{7}{c}{ Actual Productivity (ton/h) } \\
\hline & \multicolumn{3}{c}{ Serrated Edge Cutter Disc } & \multicolumn{3}{c}{ Smooth Edge Cutter Disc } \\
\cline { 2 - 9 } Cutter Disc Speed (rpm) & \multicolumn{3}{c}{ Cutter Disc Tilt Angle ( ${ }^{\circ}$ ) } & \multicolumn{3}{c}{ Cutter Disc Tilt Angle $\left(^{\circ}\right.$ ) } \\
\cline { 2 - 10 } & $\mathbf{0}$ & $\mathbf{1 5}$ & $\mathbf{3 5}$ & $\mathbf{5 0}$ & $\mathbf{0}$ & $\mathbf{1 5}$ & $\mathbf{3 5}$ & $\mathbf{5 0}$ \\
\hline 400 & 6.87 & 7.45 & 8.90 & 6.34 & 4.89 & 5.61 & 6.62 & 4.55 \\
500 & 7.56 & 8.25 & 9.59 & 7.16 & 5.35 & 6.15 & 7.06 & 5.10 \\
700 & 8.26 & 9.16 & 11.37 & 7.86 & 5.94 & 7.05 & 7.97 & 5.78 \\
900 & 9.02 & 10.04 & 12.56 & 8.63 & 6.58 & 8.17 & 9.04 & 6.28 \\
\hline
\end{tabular}

\subsection{Cabbage Damage}

Cutter disc tilt angle and type of edge cutter disc are the principal parameters governing the cabbage damage of the fabricated cabbage harvester prototype. The results in Table 3 show that generally increasing the cutter disc tilt angle from 0 to $35^{\circ}$ produced less cabbage damage percentage in both cases of a smooth and serrated edge. After $35^{\circ}$ the damage started to increase again for both types with the highest cabbage damage recorded at $0^{\circ}$ with a smooth edge. For the serrated edge cutter disc at cutter disc speed of $900 \mathrm{rpm}$, increasing the cutter disc tilt angle from 0 to $35^{\circ}$ decreased the average cabbage damage values from 7.89 to $3.8 \%$, respectively. Vice versa, when increasing the average values of cutter disc angle from 35 to $50^{\circ}$, cabbage damage increased from 3.8 to $6.38 \%$, respectively.

Table 3. Effect of cutter disc and tilt angle on cabbage damage.

\begin{tabular}{ccccccccc}
\hline & \multicolumn{3}{c}{ Cabbage Damage (\%) } \\
\hline & \multicolumn{3}{c}{ Serrated Edge Cutter Disc } & \multicolumn{3}{c}{ Smooth Edge Cutter Disc } \\
\cline { 2 - 9 } Cutter Disc Speed (rpm) & \multicolumn{3}{c}{ Cutter Disc Tilt Angle $\left(^{\circ}\right.$ ) } & \multicolumn{3}{c}{ Cutter Disc Tilt Angle $\left(^{\circ}\right.$ ) } \\
\cline { 2 - 9 } & $\mathbf{0}$ & $\mathbf{1 5}$ & $\mathbf{3 5}$ & $\mathbf{5 0}$ & $\mathbf{0}$ & $\mathbf{1 5}$ & $\mathbf{3 5}$ & $\mathbf{5 0}$ \\
\hline 400 & 18.11 & 14.31 & 6.78 & 15.89 & 21.34 & 16.43 & 11.66 & 19.12 \\
500 & 15 & 12 & 5.28 & 12 & 18 & 14.63 & 10.34 & 16.42 \\
700 & 11 & 8 & 4.34 & 9.88 & 15.22 & 11.8 & 8.84 & 13.23 \\
900 & 7.89 & 4.73 & 3.8 & 6.38 & 12.65 & 8.14 & 7.21 & 9.78 \\
\hline
\end{tabular}

For the smooth edge cutter disc at cutter disc speed $900 \mathrm{rpm}$, by increasing the cutter disc tilt angle from 0 to $35^{\circ}$, the average values of cabbage damage decreased from 12.65 to $7.21 \%$, respectively. Vice versa, when increasing the cutter disc angle from 35 to $50^{\circ}$, the average values of cabbage damage increased from 7.21 to $9.78 \%$, respectively.

\subsection{Power Required and Specific Energy Requirement}

The results in Table 4 show that, for the serrated edge cutter disc at cutter disc rotational speed of $900 \mathrm{rpm}$, by increasing the cutter disc tilt angle from 0 to $35^{\circ}$, power requirements decreased with the average values ranging from 2.90 to $2.28 \mathrm{~kW}$, respectively, while increasing the tilt angle from 35 to $50^{\circ}$ increased power requirements with the average values ranging from 2.28 to $2.79 \mathrm{~kW}$, respectively.

Similar to the results obtained with the serrated edge, with the smooth edge cutter disc at cutter disc speed $900 \mathrm{rpm}$, increasing cutter disc tilt angle from 0 to $35^{\circ}$ decreased power requirement with the average values ranging from 3.06 to $2.49 \mathrm{~kW}$, respectively. After $35^{\circ}$ tilt angle, the power requirement increased with average values ranging from 2.49 to $2.86 \mathrm{~kW}$, respectively. 
From the obtained results it is obvious that specific energy requirements for the serrated edge cutter disc at cutter disc speed $900 \mathrm{rpm}$, by increasing cutter disc tilt angle from 0 to $35^{\circ}$, specific energy requirements decreased with average values ranging from 0.32 to $0.18 \mathrm{~kW} \mathrm{h/ton,} \mathrm{respectively.} \mathrm{After}$ $35^{\circ}$ tilt angle, specific energy requirements increased again with average values ranging from 0.18 to $0.32 \mathrm{~kW} \mathrm{h/ton,} \mathrm{respectively.}$

Table 4. Power required and specific energy requirements.

\begin{tabular}{|c|c|c|c|c|c|c|c|c|}
\hline \multicolumn{9}{|c|}{ Power Requirements (kW) } \\
\hline \multirow{3}{*}{ Cutter Disc Speed (rpm) } & \multicolumn{4}{|c|}{ Serrated Edge Cutter Disc } & \multicolumn{4}{|c|}{ Smooth Edge Cutter Disc } \\
\hline & \multicolumn{4}{|c|}{ Cutter Disc Tilt Angle $\left(^{\circ}\right)$} & \multicolumn{4}{|c|}{ Cutter Disc Tilt Angle $\left({ }^{\circ}\right)$} \\
\hline & 0 & 15 & 35 & 50 & $\mathbf{0}$ & 15 & 35 & 50 \\
\hline 400 & 1.88 & 1.69 & 1.55 & 1.73 & 1.94 & 1.75 & 1.69 & 1.80 \\
\hline 500 & 2.04 & 1.94 & 1.80 & 1.96 & 2.24 & 2.00 & 1.86 & 1.96 \\
\hline 700 & 2.37 & 2.04 & 1.90 & 2.10 & 2.53 & 2.28 & 1.96 & 2.04 \\
\hline 900 & 2.90 & 2.51 & 2.28 & 2.79 & 3.06 & 2.77 & 2.49 & 2.86 \\
\hline \multicolumn{9}{|c|}{ Specific Energy Requirement, (kW h/ton) } \\
\hline \multirow{3}{*}{ Cutter Disc Speed (rpm) } & \multicolumn{4}{|c|}{ Serrated Edge Cutter Disc } & \multicolumn{4}{|c|}{ Smooth Edge Cutter Disc } \\
\hline & \multicolumn{4}{|c|}{ Cutter Disc Tilt Angle $\left({ }^{\circ}\right)$} & \multicolumn{4}{|c|}{ Cutter Disc Tilt Angle $\left(^{\circ}\right)$} \\
\hline & 0 & 15 & 35 & 50 & $\mathbf{0}$ & 15 & 35 & 50 \\
\hline 400 & 0.27 & 0.23 & 0.17 & 0.27 & 0.40 & 0.31 & 0.26 & 0.39 \\
\hline 500 & 0.27 & 0.23 & 0.19 & 0.27 & 0.42 & 0.32 & 0.26 & 0.38 \\
\hline 700 & 0.29 & 0.22 & 0.17 & 0.27 & 0.43 & 0.32 & 0.25 & 0.35 \\
\hline 900 & 0.32 & 0.25 & 0.18 & 0.32 & 0.46 & 0.34 & 0.28 & 0.45 \\
\hline
\end{tabular}

The optimum specific energy requirement for the fabricated prototype $(0.18 \mathrm{~kW} \mathrm{h/ton})$ was achieved at $35^{\circ}$ serrated cutter disc tilt angle and an average forward speed of $1.5 \mathrm{~km} / \mathrm{h}$; these effects are in line with the outcomes of [17], who stated that the lowest cutting energy was about $3.68 \mathrm{~J} \mathrm{at} 0.5 \mathrm{~cm}$ branch diameter of a fig, $20^{\circ}$ bevel angle and $10 \% \mathrm{MC}$ for cutting by a serrated knife. The specific energy requirement increased during the cutting process which was observed by the high cutter disc speed increasing.

\subsection{Operating Cost}

The results in Table 5 indicate that, for the serrated edge cutter disc at cutter disc speed $900 \mathrm{rpm}$, increasing the cutter disc tilt angle from 0 to $35^{\circ}$ decreased operating cost from 3.80 to $3.66 \$ / \mathrm{h}$, respectively, while increasing the tilt angle from 35 to $50^{\circ}$ increased operating cost from 3.66 to $3.78 \$ / \mathrm{h}$, respectively.

Table 5. Effect of cutter disc and tilt angle on operating cost.

\begin{tabular}{ccccccccc}
\hline & \multicolumn{3}{c}{ Operating Cost (\$/h) } \\
\hline & \multicolumn{3}{c}{ Serrated Edge Cutter Disc } & \multicolumn{3}{c}{ Smooth Edge Cutter Disc } \\
\cline { 2 - 10 } Cutter Disc Speed (rpm) & \multicolumn{3}{c}{ Cutter Disc Tilt Angle $\left(^{\circ}\right)$} & \multicolumn{3}{c}{ Cutter Disc Tilt Angle $\left(^{\circ}\right.$ ) } \\
\cline { 2 - 10 } & $\mathbf{0}$ & $\mathbf{1 5}$ & $\mathbf{3 5}$ & $\mathbf{5 0}$ & $\mathbf{0}$ & $\mathbf{1 5}$ & $\mathbf{3 5}$ & $\mathbf{5 0}$ \\
\hline 400 & 3.56 & 3.52 & 3.48 & 3.53 & 3.57 & 3.53 & 3.52 & 3.54 \\
500 & 3.60 & 3.57 & 3.54 & 3.58 & 3.65 & 3.59 & 3.55 & 3.58 \\
700 & 3.67 & 3.60 & 3.56 & 3.61 & 3.71 & 3.66 & 3.58 & 3.60 \\
900 & 3.80 & 3.71 & 3.66 & 3.78 & 3.84 & 3.77 & 3.70 & 3.79 \\
\hline
\end{tabular}


For the smooth edge cutter disc at cutter disc speed $900 \mathrm{rpm}$, by increasing the cutter disc tilt angle from 0 to $35^{\circ}$, operating cost decreased from 3.84 to $3.70 \$ / \mathrm{h}$, respectively. Vice versa, from 35 to $50^{\circ}$, operating cost increased from 3.70 to $3.79 \$ / \mathrm{h}$, respectively.

This can be attributed to the high influence of cutter disc tilt angle on decreased operating cost, and operating cost of cutter disc tilt angle is attributed to higher actual productivity increase rather than increase of the machine cost. In manual harvesting, the cost per hectare costs about $\$ 885$ to be harvested manually for $6 \mathrm{~h}$, in addition to the need for a full day to harvest it, by about 115 workers. It is noticed that 1 hectare accumulated cabbage must be handled by 57 workers to receiving vehicles.

\section{Conclusions}

This research aimed to fabricate a harvester prototype for cabbage. It is recommended to harvest Egyptian cabbage by serrated edge cutter disc which produces the optimum results, and operate it at an average forward speed of $1.5 \mathrm{~km} / \mathrm{h}, 900 \mathrm{rpm}$ disc speed, and cutter disc tilt angle $35^{\circ}$ producing actual productivity of $12.56 \mathrm{ton} / \mathrm{h}$, cabbage damage of $3.8 \%$, the power requirements of $2.28 \mathrm{~kW}$, the specific energy requirement of $0.18 \mathrm{~kW} \mathrm{h/ton.,} \mathrm{and} \mathrm{operating} \mathrm{cost} \mathrm{of} 3.66 \$ / \mathrm{h}$. It was found that the good performance of the prototype for harvesting cabbage saved labor, energy, time, and cost. The research work presented in this paper can effectively improve the working efficiency of harvesting Egyptian cabbage and the agricultural mechanization level.

Author Contributions: Conceptualization, M.I.E.D. and A.M.E.S.; methodology and investigation, M.I.E.D. and A.M.E.S.; writing-original draft preparation, M.I.E.D. and A.M.E.S.; primitive and final field experiments, M.I.E.D. and A.M.E.S.; writing-review and editing, M.I.E.D. and A.M.E.S. Both authors have read and agreed to the published version of the manuscript.

Funding: This research received no external funding.

Acknowledgments: The authors thank both Mohamed El Shal and Adel H. Elmetwalli for their cooperation in reading and reviewing the research paper, and we thank our family members.

Conflicts of Interest: The authors declare no conflict of interest.

\section{References}

1. FAO. FAO, 2018. Production Crops All Data. FAOSTAT; FAO: Rome, Italy, 2018.

2. Wilhoit, J.H.; Schertz, L.M.; Vaughan, D.H.; Byler, R.K. Measuring broccoli stalk cutting forces. Appl. Eng. Agric. 1989, 5, 324-328. [CrossRef]

3. Wilhoit, J.H.; Vaughan, D.H. A powered cutting device for selectively harvesting broccoli. Appl. Eng. Agric. 1991, 7, 14-20. [CrossRef]

4. Chagnon, R.; Charles, M.T.; Fortin, S.; Boutin, J.; Lemay, I.; Roussel, D. Development of a cabbage harvester. In Proceedings of the ASAE Annual Meeting, St. Joseph, MI, USA, 1-4 August 2004. Paper Number 041025.

5. Kepner, R.A.; Bainer, R.; Barger, E.L. Principles of Farm Machinery; AVI Publishing Company Inc.: Westport, CT, USA, 1978.

6. Kanamitsu, M.; Yamamoto, K. Development of a Chinese cabbage harvester. JARQ Jpn. Agric. Res. Q. 1996, $30,35-41$.

7. Casada, J.H.; Walton, L.R.; Bader, M.J. Single-pass harvesting of broccoli. Appl. Eng. Agric. St. Joseph Mich. 1989, 5, 463-466. [CrossRef]

8. Shearer, S.A.; Jones, P.T.; Casada, J.H.; Swetnam, L.D. A cut-off saw mechanism for selective harvest of broccoli. Trans. ASAE 1991, 34, 1623-1628. [CrossRef]

9. Bon, T.A. Development of a Single-Pass Mechanical Broccoli Harvester and Optimization of the Hydraulic System. Ph.D. Thesis, North Dakota State University, Fargo, ND, USA, 2003. Order No. 3099329.

10. Reza, T.K. Paddy stems cutting energy and suggested blade optimum parameters. Pak. J. Biol. Sci. 2007, 10, 4523-4526. [PubMed]

11. Du, D.D.; Wang, J.; Qiu, S.S. Analysis and test of splitting failure in the cutting process of cabbage root. Int. J. Agric. Biol. Eng. 2015, 8, 27-34. 
12. Gupta, C.; Oduori, F. Design of the revolving knife-type sugarcane base cutter. Trans. Asabe 1992, 35, 1747-1752. [CrossRef]

13. Ghahraei, O.; Ahmad, D.; Khalina, A.; Suryanto, H.; Othman, J. Cutting tests of kenaf stems. Trans. Asabe 2011, 54, 51-56. [CrossRef]

14. Du, D.D.; Xie, L.; Wang, J.; Deng, F. Development and tests of a self-propelled cabbage harvester in China. In Proceedings of the ASABE Annual International Meeting, Orlando, FL, USA, 17-20 July 2016.

15. ASAE. ASAE Standards, 2012. S358.2: Moisture Measurement_Forages; ASAE: St. Joseph, MI, USA, 2012.

16. Hunt, D. Farm Power and Machinery Management, 8th ed.; Ames Iowa State University Press: Iowa City, IA, USA, 1983; pp. 29, 69-70.

17. El Shal, A.M.; Awny, A. Energy consumption during cutting tree branches of fig (Ficus carica). J. Soil Sci. Agric. Eng. Mansoura Univ. 2019, 10, 465-470.

Publisher's Note: MDPI stays neutral with regard to jurisdictional claims in published maps and institutional affiliations.

(C) 2020 by the authors. Licensee MDPI, Basel, Switzerland. This article is an open access article distributed under the terms and conditions of the Creative Commons Attribution (CC BY) license (http://creativecommons.org/licenses/by/4.0/). 